Marine Biology

Volume 150, Number 3 / January, 2007 : Page 471-485

http://dx.doi.org/10.1007/s00227-006-0340-2

(CXXX Springer Science+Business Media

The original publication is available at http://www.springerlink.com
Archimer, archive institutionnelle de l'Ifremer http://www.ifremer.fr/docelec/

\title{
Biorheological properties of intertidal organic fluff on mud flats and its modification of gill ventilation in buried sole Solea solea
}

\author{
Ian R. Jenkinson ${ }^{1}$, Guy Claireaux ${ }^{2}$ and Patrick Gentien ${ }^{3}$ \\ ${ }^{1}$ Agence de Conseil et de Recherche Océanographiques, Lavergne, \\ F-19320 La Roche Canillac, France \\ Tel: +33 5552919 48; $\quad$ Fax: +33 5552919 82; $\quad$ Mobile: +33 608891362 \\ ian.jenkinson@wanadoo.fr \\ ${ }^{2}$ CNRS, UMR 5171, Station Méditerranéenne de L'Environnement Littoral, 1, Quai de la Daurade, F-34200 Sète, \\ France. \\ guy.claireaux@univ-montp2.fr \\ ${ }^{3}$ IFREMER, Place du Séminaire, BP 5, L'Houmeau, F-17137 France. \\ patrick.gentien@ifremer.fr
}

\begin{abstract}
:
Intertidal mudflats are important nursery grounds for juveniles of many fish species. However, they are being used increasingly to farm bivalve molluscs, which produce large amounts of organic "fluff", overlying the mud. Fish such as sole, Solea solea, hide in this fluff from potential predators, but the energy consumed by respiring the fluff may be high due to its biorheological properties. We developed an ichthyoviscometer. It incorporates a freshly killed fish as a viscometer, and we developed it to measure the rheological properties of fluids and suspensions, including fluff, at scales encompassing those in gill ventilation. We have shown that the rheological behaviour of fluff is close to that of a gel with a yield stress strongly dependent on particulate organic matter concentration ([POM]). This has allowed us to model fluff flow through the gill channels in living sole as a function of fish size and [POM], showing that in a 26-g sole, fluff would halve flow at a [POM] value of $3.2 \mathrm{~g} . \mathrm{L}^{-1}$, and stop it at 3.4 .
\end{abstract}




\section{INTRODUCTION}

The French Atlantic coast comprises a series of intertidal mud flats, which shelter important nurseries for juveniles of numerous fish species, particularly the common sole, Solea solea (Koutsikopoulos et al, 1989). The common sole is a major resource in the Bay of Biscay, where 1800 tons of sole are harvested yearly (Léauté and CaillMilly, 2003). However, since 1993 the spawning biomass of the Bay of Biscay stock has been undergoing a constant decline and it is currently at risk, with the lowest level of recruitment of the last 20 years recorded for the year class 1999 (Anonymous, 2003).

As crucial nursery grounds for juvenile fish, intertidal mudflats are coming under increasing socio-economic pressure, particularly by shellfish farming. The mud flats of Marennes-Oléron and the Anse de L'Aiguillon (Fig. 1), in particular, are among the most intensively farmed in Europe, sustaining a total biomass of 90,000 tons of oysters and 10,000 tons of mussels. Based on Pouvreau (1999), it is readily estimated that the total volume of water that transits hourly through the gills of these filterfeeding bivalves ranges from $3 \times 10^{6}$ to $6 \times 10^{6} \mathrm{~m}^{3}$. As water moves across the bivalve gills, suspended particles are retained, mixed with mucus and sorted according to their shape, size and nutritional value before being ingested. The non digestible fraction of the ingested food will be rejected as faeces. Particles with no nutritive use (essentially mineral) are not ingested but are released as pseudofaeces. Bivalve faeces and pseudofaeces accumulate in the vicinity of the shellfish farms and, in the MarennesOléron Bassin, oyster farming generates $\sim 6$ tonnes (dry matter) of biodeposit per hectare per day (Sornin et al., 1986). The accumulation of biodeposit on the bottom contributes to the development of a layer of organic aggregates termed "fluff". This fluff layer lies up to several mm thick at the sediment-water interface, rich in exopolysaccharides (EPS) produced largely by populations of interstitial and epipelic algae and bacteria (Barillé 2000). It is believed that these cells exude a mucilage layer to stabilise the fluff against water turbulence (Decho 1990).To hide from predators juvenile sole bury into the fluff layer, but it has not been known to what extent EPSenriched fluff is liable to alter the energetics of gill ventilation and gas-exchange dynamics across their respiratory epithelia.

To reproduce, at the proper scale, the actual physical processes involved during the fish ventilation cycle, we investigated the effect of EPS water load on ventilatory flow using a slightly modified version of the ichthyoviscometer used by Jenkinson and Arzul $(1998,2002)$.

The present work was carried out in the long-term context of developing methods and providing information to help model natural and socio-economic effects on two types of system: (1) coastal ecosystems, (2) the global ocean and other natural waters in relation to climate and biogeochemical change. The more immediate aims are fivefold: (1) To illustrate how the measured rheological properties of organic aggregate suspensions, such as benthic organic fluff, are influenced by the shape and size of the system in which they are measured, by presenting published data obtained using sewage sludge, (2) to determine the most appropriate scale at which to investigate the rheological properties of benthic organic fluff, (3) to measure the relevant biorheological properties of the fluff, (4) to determine the major factors influencing the ventilatory flow of marine organic fluff through gills of post-metamorphosis juvenile flatfishes, (5) to improve methodology for measuring the biorheology, and hence hydrodynamics, of natural waters at scales relevant to key biological and biogeochemical

processes. 


\section{MATERIALS AND METHODS}

\section{Rationale}

If stripped of organic components, the bulk phase of seawater comprises only water and salts. This solution of small molecules and ions presents a Newtonian viscosity which is dependent on temperature and salt-content (Miyake and Koizumi, 1948), but independent of deformation rate. Organisms, particularly planktonic algae, live and metabolise in the sea, and secrete dissolved and colloidal polymers (, Bjørnsen, 1988; Passow, 2002). These secreted exopolymers (EPS) impart elasticity and excess non-Newtonian viscosity to the seawater, which has been measured by classical rheometric methods using steady or oscillating shearing in a Couette system (Jenkinson, 1986, 1993a,b; Jenkinson and Biddanda, 1995), or detected by measurement of the reduction of turbulent drag (Hoyt, 1970).

Considerable variability in the viscoelastic properties of replicates taken from the same seawater samples was ascribed by Jenkinson (1993b) to spontaneous cmscale aggregation in the sample bottles. As reviewed by Passow (2002), other workers have confirmed, by light- and electron-microscopical observation, that EPS generally exist in a spatially heterogeneous, dynamic mixture of suspended, colloidal and dissolved phases, subject to complex, quasi-fractal aggregation at scales from $\leq 1 \mu \mathrm{m}$ to $\geq 1 \mathrm{~cm}$. These EPS can aggregate as visible marine snow of $\mathrm{mm}$ to $\mathrm{cm}$ size (Alldredge et al., 1990), as transparent exopolymeric particles (TEP; $10 \mu \mathrm{m}$ to $1 \mathrm{~mm}$; Mari and Kiørboe, 1995), and organic polymers can also spontaneously form colloidal aggregates $(\leq 1 \mu \mathrm{m}$; Wells and Goldberg, 1993).

Like seawater but more thickly (Verdugo et al., 2004), intertidal and shallow subtidal mud is rheologically thickened by EPS produced mainly by interstitial diatoms (Sutherland et al., 1998; Barillé and Cognie, 2000; Underwood et al., 2004). Fine submarine sediments also contain protozoa and a rich flora of bacteria, binding to each other and to adjacent mineral grains with polymeric fibrils to form $\leq 25-\mu \mathrm{m}$ aggregates considered similar in structural features to those of marine snow aggregates (Decho, 1990; Ransom et al., 1999). Incorporated in the organic fluff layer studied here, which overlies mud, are also large quantities of algae, particularly diatoms, which appear to be the main origin of rheologically thickening material whose abundance and production is ultimately driven by faeces and pseudofaeces production by the cultured bivalves. Such propensity to gel by EPS is dominated by acidic polysaccharides (Olianas et al., 1995; Verdugo et al., 2004).

Aggregate networks of colloidal particles are well known by rheologists to gel above a critical concentration (as a general rule), and, as illustrated in Fig. 2, the resultant yield stress can be highly scale-dependent. Furthermore, the yield stress in compactive flow can exceed that in shear flow by up to two orders of magnitude (Buscall et al, 1988).

At low Reynolds numbers, the measured rheological properties of homogeneous (i.e. monodisperse) materials is independent of rheometer or viscometer geometry. However for heterogeneously aggregated, or "lumpy", materials, the presence of aggregates of different sizes and different rheological properties means that measured rheological properties of the suspension/solution will depend on the scales of the flow and hence on the shape and size of the measuring apparatus. This is illustrated by Spinosa and Lotito's (2003) measurements of the yield stress of a single batch of sewage sludge measured using a capillary tube-type viscometer, the "kasumeter". The kasumeter was described by Schulze et al. (1991) and is currently proposed as a European Union standard (HORIZONTAL Report No. 21, 2004; http://www.ecn.nl/docs/society/horizontal/hor21_flowability.pdf) for the 
measurement of yield stress in sewage sludges (Fig. 3). The material to be measured is poured into the vertical cylinder and is allowed to flow out of the horizontal tube until it stops. At this point the height difference, $h$, between the surface of the liquid and the level of the tube is used to measure the yield stress from Eq. 3. Yet as Spinosa and Lotito found, sludge yield stress is a function not only of sludge concentration but also of tube diameter (Fig. 2). Sewage sludge is composed mainly of active bacteria and quasi-fractal aggregates of bacteria-secreted EPS (Busch and Stumm, 1968; Li and Ganczarczyk, 1986), so its physical structure is closely comparable to our benthic fluff. Moreover, both show a yield stress. Measurement of their rheology thus invites somewhat similar approaches.

An ichthyoviscometer has already been developed to measure the rheological effects of EPS secreted in culture and in the sea by ichthyotoxic and other planktonic algae. EPS can add a shear-thinning viscosity or even a yield stress to the seawater solvent viscosity (Jenkinson and Arzul, 1998). An ichthyoviscometer has also been used as a laboratory tool to measure fluidification of algal EPS by the addition of cystein-based compounds (Jenkinson and Arzul, 2002). In both this previous and the present work, we used the gill passages of a killed fish as the geometry of measurement, and imposed values of cross-gill hydrostatic pressure difference $P$ around those developed by the same species of fish in vivo. The measurement geometry, scales and surface properties used for the measurement were thus similar to those relevant to the problem of interest, in this case reduction of cross-gill ventilatory flow in a living fish by rheological thickening of the seawater due to algal EPS.

Despite the large number of studies conducted, our understanding of the relationship between water ventilation flow and the anatomy of the fish buccobranchial cavity (including the gill passages) is relatively poor. During the ventilatory cycle a continuous, unidirectional flow of water is generated by the action of a buccal "force" pump combined with an opercular "suction" pump, these two pumps operating out of phase (Shelton, 1970; Hughes and Morgan, 1973; FerryGraham, 1999). Flow is difficult to measure inside a fish's head, so relative pressures in the orophayngeal and parabranchial cavities have been used as an indicator of flow direction. When the mouth is closed a high pressure is created by the constricting buccal cavity. The pressure in the branchial cavity also increases but less than in the buccal cavity. The opercular flap is then opened and water flows through the gills and thence to the outside. The mouth is then opened and the opercular flap is closed. A low pressure is created in the buccal cavity by its expansion. This draws water from the outside into the buccal cavity. At the same time the branchial cavity is also expanding but its pressure is kept lower than in the buccal cavity allowing water to continue its one-way flow through the gill arches. The pressure difference between the buccal and opercular cavities is induced by the resistance created by the sieve formed by the gill filaments. The distribution of hydrostatic pressures within the buccal and branchial chambers remains a debated issue with potential incidences when assessing gill resistance and the energetics of fish breathing (Holeton and Jones, 1975). The pores of the gill sieve can be adjusted by changing the angles of the gill filaments using adductor and abductor muscles. In this way the gill resistance, and thus the differential pressure across the bucco-branchial chamber can be regulated. It has been shown that gills behave like a low-pass filter, damping the amplitude of the velocity oscillation during the ventilatory cycle (Malte, 1989). This author also suggested that interlamellar water flow is pulsatile and that the possibility for backflow exists (see also Hughes, 1960; Hughes and Morgan, 1973; Ferry-Graham, 1999; Summers and Ferry-Graham, 2001).We further suggest that evolutionary pressures may have led to a trade-off between laminar flow, which minimises energy requirements, and more complex, somewhat turbulent flow patterns to erode boundary layers and thereby 
maximise the gas diffusion gradient between the water and the blood vasculature (see Piiper and Scheid, 1984). If so, water flow would be more turbulent than Reynolds numbers calculated from passage dimensions might suggest. Study of small-scale flow patterns in the gill passages would help to test our suggestion.

To measure rheological properties of fluff in fish gill passages, and to escape from the need to examine the various scales involved, we considered that the gill passages of a dead juvenile sole were the most appropriate measuring device. We also sequentially varied cross-gill hydrostatic pressure $(P)$ from 270 to $10 \mathrm{~Pa}$, the lower end of this range being representative of the pressure generated in vivo (Eq. 11, below).

We also improved the original ichthyoviscometer design. To deal with the tendency of fluff suspension to sediment during the experiment, we adapted the small reservoir to receive a magnetic stirrer. Furthermore we used pressure probes to measure $P$, instead of visual observation of the difference in water level; this improvement allowed machine-acquisition of $P$ with time.

\section{The fish}

Soles (Solea solea L.), late 0-group, length $12-15 \mathrm{~cm}$, mass 17-30 g) were obtained by trawling about $1 \mathrm{~km}$ offshore in the Pertuis Breton (Fig. 1). Upon arrival at the laboratory fish were transferred to indoor rearing tanks $\left(1 \mathrm{~m}^{2}\right)$ the bottom of which was covered with $1 \mathrm{~cm}$ of sand. During their first week in the laboratory, three sanitary antibiotic treatments were applied 2-3 days apart, after which an additional 4week acclimation period was allowed. During that period, fish were fed twice a week with fresh mussel and oyster flesh.

\section{The fluff}

Fluff was skimmed with a spoon from the sediment surface on the shore around the level of Low Water Neap Tides at Pampin, L'Houmeau, CharenteMaritime, France (Lat. $46^{\circ} 31 . N$, Long. $01^{\circ} 10 . W$ ) (Fig. 1). This sediment lay close to abandoned iron frames, initially installed for oyster culture, and which were thickly encrusted with wild oysters Crassostrea gigas. The sediment immediately below the fluff layer sampled was aerobic. A complete description of the grain size distribution and particulate organic matter composition of the surficial sediment can be found in Galois et al. (2000). Daily sampled sediment was thoroughly mixed using an electric paint stirrer. Equal quantities of this homogenised fluff and seawater were mixed gently, so as to minimise breaking the polymeric molecules, to make up one litre. The mixture was left to stand for 1 hour, after which time it had formed three layers. The top layer is clear, the middle layer is mainly of organic fluff, and the bottom layer is rich in inorganic particles. The sediment was then decanted to obtain only the middle and upper layers, giving a material similar to that in the layer occupied by the sole in the field. Experimental fluff was withdrawn by syringe from below the surface, stored separately, and mixed gently using the paint stirrer, immediately before measurements for dry weight (DW), ash-free dry weight (AFDW) and use in experiments. This material could then be diluted with seawater to give a range of concentrations for our experiments.

Seawater was obtained from the CREMA circulation system. Temperature and salinity of both seawater and the sediment was measured using a WTW T/S probe (Weilheim, Germany).

The salinity of the fluff suspension collected was found to be $22( \pm 2)$ and was diluted with water of the same salinity. The temperature of the apparatus and contents during experiments was $15 \pm 2^{\circ} \mathrm{C}$. Seawater density was thus $1016 \mathrm{~kg} \cdot \mathrm{m}^{-3}$ (Cox et al., 
1970), chlorinity 12.17 (Culkin and Cox, 1966) and thus viscosity in the absence of fluff $1.224 \mathrm{mPa} \cdot \mathrm{s}\left[=\mathrm{kg} \cdot \mathrm{m}^{-1} \cdot \mathrm{s}^{-1}\right]$ (Miyake and Koizumi, 1948).

\section{The flow apparatus}

The ichthyoviscometer (Fig. 4) consisted of a small reservoir (SR) and a large one (LR). The SR consisted of a polyethylene cylinder of diameter $6 \mathrm{~cm}$ and height $14 \mathrm{~cm}$, in containing the experimental material (water or fluff suspension). This reservoir was equipped with a magnetic stirrer bar in order to keep the fluff in homogeneous suspension. The LR $\left(11 \mathrm{~cm}\right.$ in height and $28.3 \mathrm{~cm}^{2}$ in cross-sectional area), of Plexiglas, contained the experimental dead sole. A horizontal PVC tube (diameter $1 \mathrm{~cm}$ ) connected the two reservoirs. This tube was fitted with a polyethylene tap and a nozzle. A tapering tube, of length $3.5 \mathrm{~cm}$, and of diameter $0.6 \mathrm{~cm}$ at its intake and $0.3 \mathrm{~cm}$ at its outlet, was fitted to the nozzle and the narrow outlet end was connected to the dead sole (see below). By these means, when the water level in the SR was higher than that in the LR and thus a hydrostatic pressure difference existed, experimental material was able to flow from the SR, through the connecting tubing, the tap, the tapering tube and the sole's buccal and branchial cavities, into the LR.

\section{Pressure probe}

The hydrostatic pressure between the SR and the LR was measured via two catheters, each placed in one of the reservoirs and both connected to a differential pressure sensor (Sureness Ultra Low Pressure Sensors, Honeywell, Inc.). Its output was recorded at $2 \mathrm{~Hz}$ through a homemade data acquisition module to a PC running Labview software ( G. Guillou, CREMA-L’Houmeau).

The zero was determined after introducing clean seawater into both reservoirs of the apparatus, ensuring that no bubbles remained in the flow-ways. The tap was opened to equilibrate water levels in the SR and the LR.

\section{Experimental protocol}

So that the experimental conditions were as realistic as possible, we used freshly killed sole. Anaesthesia induced increased gill mucus secretion, and did not completely eliminate muscular reflexes (Jenkinson, personal observation). Furthermore we were concerned that anaesthetic chemicals might change the biorheological properties of the fluff, the surface properties of the gills, or the size and shape of the gill passages through shrinkage or swelling of tissues. For these reasons, we killed the fish quickly and as humanely as possible by pithing the brain with a scalpel.

The dead sole was then placed in the experimental setup (Fig. 4) so that the tapering tube entered the mouth almost up to the first branchial arch. The mouth and the branchial channels were kept open to an extent as reproducible as possible for the different fish. The tapering tube was sealed in the mouth using instant glue (Loctite 401). The tip of the operculum (eyed side) was cut off. This was because stresses in the tissues tend to close it in dead fish, and such closure would have added extra hydrostatic pressure opposing flow.

With the fish in place, the tap was opened to allow experimental fluid to flow from the SR to the LR, and the change in pressure difference between the two reservoirs was recorded over time. Between successive trials, the connecting tube and the gill cavity of the fish were thoroughly flushed with clean seawater, and care was taken to exclude bubbles.

In order to measure the material properties of the fluff over a wide range of hydrostatic pressure difference, changes in $P$ were recorded starting at a maximal 
value $270 \mathrm{~Pa}$ measured at $\mathrm{t}=0$, and for the next $180 \mathrm{~s}$, or until flow had effectively stopped (e.g. Fig. 5). This asymptote corresponds to a yield stress.

Although the maximum value of $P$ we imposed considerably exceeds the value of $P$ achieved in natura (Eq. 11), measurement of flow rate over a wide range of $P$ allowed more comprehensive understanding to be gained of the rheological properties of the fluff.

The experimental work giving the results reported here was carried out at the IFREMER-CNRS CREMA Laboratories at L'Houmeau from April to July 2003.

\section{Calculations and modelling}

If the level in SR is initially higher than that in LR, and the tap is opened, then the volume of liquid having flowed from SR to LR is:

$$
V=\left(H_{0}-H_{1}\right) \cdot A_{L R} \cdot A_{S R} /\left(A_{L R}-A_{S R}\right) \quad\left[\mathrm{m}^{3}\right]
$$

where $A_{\mathrm{LR}}$ and $A_{\mathrm{SR}}$ are the surface areas [m²] of the large and small reservoirs respectively and $H_{0}$ and $H_{1}$ are the initial and final differences in water level [m] (Jenkinson and Arzul, 1998).

The flow rate at a given time, $\mathrm{t}$

$$
F(t)=\frac{\partial V}{\partial t} \quad\left[\mathrm{~m}^{3} \cdot \mathrm{s}^{-1}\right]
$$

For the apparatus used in the present experiments, $A_{\mathrm{LR}}$ was $0.297 \mathrm{~m}^{2}$ and $\mathrm{A}_{\mathrm{SR}}$ was $0.0283 \mathrm{~m}^{2}$ (Eq. 1). For each 1-m change in $H$, the volume flowing from the SR to the LR was thus $0.0313 \mathrm{~m}^{3}$. Since the hydrostatic pressure difference exerted by a head $H$ of material of density $\rho$ is

$P=H \cdot \rho \cdot g$

$$
\left[\mathrm{Pa}=\mathrm{kg} \cdot \mathrm{m}^{-1} \cdot \mathrm{s}^{-2}\right]
$$

where $g$ is acceleration due to gravity, $9.8 \mathrm{~m} . \mathrm{s}^{-2}$. In the present apparatus, each change in $P$ by $1 \mathrm{~Pa}$ is equivalent to a change in head of $1 \mathrm{~m} /(\rho . g)$ equal to $0.100 \mathrm{~mm}$. An apparatus of this design can thus be ascribed a constant, $J$, which describes the volume flowed per unit change in $P$,

$J=V / P$

$$
\left[\mathrm{m}^{3} \cdot \mathrm{Pa}^{-1}=\mathrm{m}^{4} \cdot \mathrm{kg}^{-1} \cdot \mathrm{s}^{2}\right]
$$

For the present apparatus, $J$ was therefore $3.14 \times 10^{-6} \mathrm{~m}^{4} \cdot \mathrm{kg}^{-1} \cdot \mathrm{s}^{-2}$. From Eq. 4, the volume of test material $V$ flowing through a fish during complete flow trial in which $P$ decreases from 270 to 0 Pa was $J . P=845 \mathrm{~cm}^{3}$.

For trials without fluff, where the water viscosity and the flow geometry can both be assumed constant, and the Reynolds number (see section 2.8) remains low (inertial effects insignificant), thus avoiding any turbulent resistance to flow,

$F(t)=P(t) /(R . J)$

$$
\left[\mathrm{m}^{3} \cdot \mathrm{s}^{-1}\right]
$$

where $R$ is the total combined resistance due to the viscosity of the fluid and the geometry of the system $\left[\mathrm{kg}^{2} \cdot \mathrm{m}^{-8} \cdot \mathrm{s}^{-3}\right]$. 
Since $R$ may be decomposed into the effective dynamic viscosity of the fluid, $\eta\left[\right.$ Pa.s $=$ kg.m $\left.\mathrm{m}^{-1} \cdot \mathrm{s}^{-1}\right]$ multiplied by a flow-geometry resistance, $K\left[\mathrm{~kg} \cdot \mathrm{m}^{-7} \cdot \mathrm{s}^{-2}\right]$,

$$
R=\eta \cdot K \quad\left[\mathrm{~kg}^{2} \cdot \mathrm{m}^{-8} \cdot \mathrm{s}^{-3}\right]
$$

$K$ is thus in principle specific for each fish.

For a Newtonian liquid flowing at low Re through a flow passage of constant geometry, the levels in the two reservoirs will approach each other asymptotically as material flows through the gills:

$$
P(t)=P(0) \cdot \mathrm{e}^{-t /(R . J)} \quad\left[\mathrm{Pa}=\mathrm{kg} \cdot \mathrm{m}^{-1} \cdot \mathrm{s}^{-2}\right]
$$

Fig. 5a,b shows an example of data from a single flow trial using pure water, with the above model fitted using $Y=0 \mathrm{~Pa}$ and $R=7.1 \mathrm{~kg}^{2} \cdot \mathrm{m}^{-8} \cdot \mathrm{s}^{-3}$.

\section{Flow regimes}

The extent to which flow in a tube is laminar or turbulent, is determined largely by the Reynolds number,

$$
R e=2 r U \rho / \eta \quad \text { [dimensionless] }
$$

where $r$ is the radius of the tube, $U$ the mean fluid velocity, and $\rho$ and $\eta$ the density and viscosity of the fluid.

In the first part of our experiments with pure water (Fig. 5a,b), the flow rate, $F$, at the highest pressure used, $\sim 270 \mathrm{~Pa}$, was close to $6 \mathrm{~cm}^{3} . \mathrm{s}^{-1}$. The radii of the mouth of the sole and of the tube close to the mouth were both close to $0.2 \mathrm{~cm}$, giving a mean streamwise flow velocity, $U=F /\left(\pi r^{2}\right) \approx 50 \mathrm{~cm} . \mathrm{s}^{-1}$. With values for $\rho$ and $\eta$ of $1016 \mathrm{~kg} \cdot \mathrm{m}^{-3}$ and $0.001 \mathrm{~kg} \cdot \mathrm{m}^{-1} \cdot \mathrm{s}^{-1}$, respectively, $R e$ is then close to 2000 in both the mouth and the tube. For comparison, in vivo measurements of water velocities in the mouth of a large carp (buccal cavity $\geq 8 \mathrm{~cm}$ ) were found to oscillate with amplitude up to $\sim 15 \mathrm{~cm} . \mathrm{s}^{-1}$, (Holeton \& Jones, 1975).

Transition from laminar to turbulent flow is normally considered to occur at $R e \approx 10^{3}$ to $10^{4}$. Turbulence in pipe flow imparts resistance to flow in addition to that already provided by the molecular viscosity $\eta$, although flow may sometimes show strong dependence on $R e$ at values as low as 1 to 100 (Massel, 1999), perhaps indicated by flow curves we found with pure seawater (e.g. Fig. 5a,b). Furthermore, to our knowledge no hydrodynamical study of ventilation flow between gill lamellae has been published.

The far smaller dimensions of the gill ways give values of $R e$ generally $<10$ in life (Hughes, 1984), however. As the greatest hydrostatic pressures (270 Pa) used in our measurements are $\sim 9$ times those produced by live fish $(\sim 30 \mathrm{~Pa})$, values of $R e$ between the gill lamellae could increase by a similar factor, but would still be well below the value of $\sim 1000$, at which turbulent viscosity in pipe flow may start to become significant relative to molecular viscosity. Mean velocities in the gill ways in life were estimated by Langille et al. (1983) to lie between 0.017 to 0.047 to 0.11 $\mathrm{cm} . \mathrm{s}^{-1}$ for seabass of, respectively, 0.23 to 26 to $837 \mathrm{~g}$ 


\section{RESULTS}

\section{Results-based model development and validation}

Fig 5 shows two examples of typical flow curves, one for filtered seawater (Fig. 5a and b) and one for $50 \%$ fluff (Fig. 5c and d). In these trials, $P$ progresses near-exponentially to a near-asymptote, 0.0 Pa for filtered seawater and $65 \mathrm{~Pa}$ for this particular flow of $50 \%$ fluff. This asymptote corresponds to a yield stress $Y$ (Barnes and Walters, 1985; Barnes et al., 1989).

By definition, an ideal gel shows a yield-stress (Cheng, 1986), Y. At deformation stress $\leq Y$, the material shows no deformation except perhaps for elastic deformation, which is perfectly recovered when the stress is removed. At deformation stress $>Y$, the material shows viscous (i.e. non recoverable) deformation $\gamma$ according to model of a Bingham plastic:

$$
P=Y+\eta \cdot \dot{\gamma} \quad\left[\mathrm{Pa}=\mathrm{kg} \cdot \mathrm{m}^{-1} \cdot \mathrm{s}^{-2}\right]
$$

where $P$ is the total modulus (deformation pressure), $Y$ is the yield stress, $\dot{\gamma}$ is the deformation rate $d \gamma / d t$ and $\eta$ is the Newtonian viscosity of the material, that is a viscosity independent of both $\gamma$ and $\dot{\gamma}$.

As shown in Eq. 7, a Newtonian liquid will flow asymptotically to approach a hydrostatic pressure difference of zero at infinite time $P(\infty)=0$ (Fig. 5a,b), whereas an ideal gel will flow asymptotically towards $P(\infty)=Y$ (e.g. Fig. 5c,d). Combining Eqs 7 and 9,

$$
P(t)=(P(0)-Y) \cdot \mathrm{e}^{-t /(R . J)}+Y \quad\left[\mathrm{~Pa}=\mathrm{kg} \cdot \mathrm{m}^{-1} \cdot \mathrm{s}^{-2}\right]
$$

$Y$ and $R$ are determined by adjusting them to give the best fit between the model and the results.

$K$ is then simply $R / \eta_{W}$ (Eq. 6), where $\eta_{W}$ is the viscosity of the solvent (here water plus salt), being $1.224 \times 10^{-3}$ Pa.s $\left[=\mathrm{kg} . \mathrm{m}^{-1} . \mathrm{s}^{-1}\right]$ (Miyake and Koizumi, 1948).

\section{Relationship between [PIM] and [POM]}

As shown in Fig. 6a, [POM] (where the square brackets denote concentration) was highly correlated with [PIM] $\left(\mathrm{r}^{2}=0.93\right)$. That $\mathrm{r}^{2}<1$ indicates that, although derived from dilution of the same stock sample, PIM and POM had undergone some differential sorting in the suspension.

\section{Effects of [PIM] and [POM] on $R$ and $Y$}

In pure seawater $([\mathrm{PIM}]=0 ;[\mathrm{POM}]=0) Y$ should be zero, but $R$ must have a positive value, varying between different fish and the morphology of their gill passages.

Intercepts ( $\pm 95 \%$ confidence limit) of the relationships between $Y$ and [PIM] or $[\mathrm{POM}]$ were respectively $-11( \pm 13)$ (Fig. 6c) or $-27( \pm 13) \mathrm{Pa}$ (Fig. 6e). One premise of our model is that $Y=0$ when [PIM] and [POM] are equal to zero. Although the intercept of $Y$ with [PIM] was not significantly different from zero, that of $Y$ with [POM] was negative. While a negative value for yield stress is physically impossible, inspection of Fig. 6e shows that the relationship of $Y$ to [POM] is non-linear, with measured values of $Y$ staying close to zero until [POM] exceeds a threshold of $\sim 3$ g.L $\mathrm{L}^{-}$ 1 . 
That the slopes of both $Y$ and $R$ showed somewhat closer relationships with [POM] $\left(\mathrm{r}^{2}=0.62\right.$ and 0.24, respectively: Fig. 6e,f) than with [PIM] $\left(\mathrm{r}^{2}=0.52\right.$ and 0.20 : Fig. $6 c, d)$ suggests that $[P O M]$ affected yield stress and high-deformation-rate flow more than did [PIM] despite the approximately 22-fold higher concentration of the latter.

Correlation, $\mathrm{r}^{2}$, of [PIM] and [POM] with $R$ (respectively 0.20 and 0.24 - Figs $6 \mathrm{~d}, \mathrm{f})$ was far lower than the corresponding values with $Y(0.52$ and 0.62$)$, reflecting that variation among the trials was higher for $R$ than for $Y$. Correlation between $R$ and $Y$ was only moderate, with $\mathrm{r}^{2}=0.27$ (Fig. $6 \mathrm{~b}$ ) and similar to that between $R$ and both [PIM] and [POM] (Fig. 6b,d), but much smaller than that between $Y$ and both [PIM] and [POM] (Figs 6c,e). In summary, $R$ varied widely among trials with only small, but statistically significant, dependence on $Y$, [PIM] and [POM].

Hughes' (1965) classical model of elasmobranch and teleost respiration supposes that the gills remain open to flow through them throughout the ventilatory cycle, yet it seems that direct observation has had to wait many years. Ferry-Graham (1999) suggested that the observed absence of a reverse flow when pressure is higher in the parabranchial than in the oesophageal cavity, could only be explained by adduction of the gill bars with consequent closing of the gills to flow. Summers and Ferry-Graham (2001) confirmed that the gill bars do adduct in an elasmobranch, thereby closing the flow passages when hydrostatic pressure is higher in the parabranchial chamber than in the oesophageal chamber. They abduct, opening the gill passages, for the rest of the cycle. If water-breathing teleosts close and open their gill passages similarly, and Summers and Ferry-Graham suggest they do, it would be expected that in dead teleosts, the passages would be lying open or closed to varying degrees, which may explain a large part of the scatter we have found in $R$ (Figs. $6 b, d, f)$. We have already found high between-individual differences in the resistance to flow in rainbow trout Oncorhynchus mykiss (Jenkinson and Arzul, 1998) and seabass Dicentrarchus labrax (Jenkinson and Arzul, unpublished). In addition, we have found $R$ to increase strongly about 4-6 hours after death in trout, seabass and other fish, associated with slime, perhaps bacterial, lining the gills (Jenkinson, personal observations).

\section{Modelling the flow in live sole as a function of fluff rheology}

Differential pressure $P$ between the buccal/oesophageal and parabranchial cavities in large fishes from about 0.68 to $3.5 \mathrm{~kg}$ ranges from about 40 to $100 \mathrm{~Pa} ; 200$ $\mathrm{Pa}$ in tuna (Hughes and Shelton, 1958; Shelton, 1970; Stevens, 1972; Ferry-Graham, 1999; Summers and Ferry-Graham, 2001; Dalla Valle et al., 2003). We have found that 0 -group sole follow this general relationship, $P$ being related to mass according to the following equation (G. Claireaux, personal measurements),

$$
P=0.25 . \mathrm{M}-1.4797 \quad\left[\mathrm{~Pa}=\mathrm{kg} \cdot \mathrm{m}^{-1} \cdot \mathrm{s}^{-2}\right]
$$

where $\mathrm{M}$ is the mass of the fish in grams. According to this equation, a sole situated in the middle of the mass range we experimentally investigated, 26 g, generates a crossgill differential pressure of $\sim 4.8 \mathrm{~Pa}$.

To provide a first approximation of water flow through the gill passages of 0 group sole of $26 \mathrm{~g}$ we have modelled flow rate $F$ as a function of [POM] and $P$, based on the relationships of $Y$ to [POM] (Fig. 6e) and $R$ to [POM] (Fig. 6f):

$$
\begin{aligned}
& Y(P O M)=-27+9 \cdot 7 \cdot[\mathrm{POM}] \text { if }>0 \text {, else } 0 \quad\left[\mathrm{~Pa}=\mathrm{kg} \cdot \mathrm{m}^{-1} \cdot \mathrm{s}^{-2}\right] \text { (Eq. 12) } \\
& R(P O M)=4.4 \times 10^{6}-0.26 \times 10^{6} \cdot[\mathrm{POM}] \quad\left[\mathrm{kg}^{2} \cdot \mathrm{m}^{-8} \cdot \mathrm{s}^{-3}\right] \quad \text { (Eq. 13) }
\end{aligned}
$$




$$
F(P O M)=\frac{P-Y(P O M)}{R(P O M)} \text { if }>0, \text { else } \quad\left[\mathrm{m}^{3} \cdot \mathrm{s}^{-1}\right]
$$

Fig. 7 shows the predicted value of the flow rate $F$ vs. [POM] for five levels of cross-gill hydrostatic pressure difference $(1,2,5,10$ and $20 \mathrm{~Pa})$. Sole able to produce such maximum values of $P$ in vivo would have respective masses of $10,14,26,46$ and 85 g (Eq. 11). (The slight positive slope of $F$ vs. [POM] for $0<[\mathrm{POM}]<2.7$ g. $\mathrm{L}^{-1}$ (Fig. 7) corresponds to the negative relationship between $R$ and [POM] between [POM] values of 0 and 2.7 g. $\mathrm{L}^{-1}$ in Fig. 6f. However, if only values between 0 and 2.7 g. $\mathrm{L}^{-1}$ in Fig. $6 \mathrm{f}$ are taken into account, the slope of $R$ vs. [POM] is not significantly different from $0(\mathrm{P}=0.3 ; \mathrm{n}=8)$. Therefore we conclude that the modelled slope of $F$ vs. [POM] in Fig. 7, although apparently positive for [POM] values less than 2.7, is statistically not significantly different from 0

As shown in Fig. 7, for a fish from 10 to $85 \mathrm{~g}$ in mass, corresponding to in vivo hydrostatic pressure of 1 to $20 \mathrm{~Pa}$, modelled flow rate $(F)$ is not significantly related to $[\mathrm{POM}]$ as long as $[\mathrm{POM}] \leq 2.7$ g. $\mathrm{L}^{-1}$. For values of $[\mathrm{POM}]>2.7$ g.L $\mathrm{L}^{-1}$, however, $F$ declines sharply with increasing [POM]. For a 10 -g sole, $F$ declines to zero (i.e. flow stops) at $[\mathrm{POM}]=2.8 \mathrm{~g} . \mathrm{L}^{-1}$ while for a $26-\mathrm{g}$ and a $85-\mathrm{g}$ sole flow stops at a respective POM concentrations of 3.3 and 4.8 g. $\mathrm{L}^{-1}$.

For a 26-g fish, corresponding to a maximum in vivo hydrostatic pressure difference of $4.8 \mathrm{~Pa}$, Appendix Fig. A.1b shows $F$ vs. [POM] with 95\% confidence limits. The Appendix describes how we derived these confidence limits. Relative to that in pure seawater, i.e. when $[\mathrm{POM}]=0$, in vivo flow through the gills of a $26-\mathrm{g}$ fish, in which maximum developed cross-gill hydrostatic pressure is $4.8 \mathrm{~Pa}$, modelled flow, with upper and lower 95\% confidence limits, is reduced by half when [POM] is 3.5 to 4.6 to 7.7 g. $\mathrm{L}^{-1}$, and stops completely at 4.2 to 5.7 to $9.1 \mathrm{~g} . \mathrm{L}^{-1}$. 


\section{DISCUSSION AND CONCLUSIONS}

If the yield stress $Y$ of material passing through fish gill passages exceeds the hydrostatic pressure difference maintained across the gills, flow will stop completely. The hydrostatic pressure difference $P$ exerted by a juvenile sole of mass $26 \mathrm{~g}$ across its gills in life is about 4.8 $\mathrm{Pa}$ (Eq 11). Fig. 7 shows that in such a sole, modelled flow will stop completely at a suspended fluff concentration equivalent to [POM] of 3.3 g. $\mathrm{L}^{-1}$, and would be halved at $[\mathrm{POM}]$ of $3.1 \mathrm{~g} . \mathrm{L}^{-1}$. This illustrates that the effect of the fluff suspension is a very strong function of concentration, once the threshold is passed, as shown further in Fig. 7. Even for a much larger fish, 85 g, exerting a $P$ value of $20 \mathrm{~Pa}$, flow would be halved in fluff with a [POM] value of $4.1 \mathrm{~g} . \mathrm{L}^{-1}$ and stop completely at 4.9 .

Lacking data on the subject, we have neglected any effect of gill-passage cross-section area on effective yield stress, as in a kasumeter capillary tube (see Fig. 2). Larger fish, however, having gill passages of greater cross-section area (Langille et al, 1983), might experience lower values of $Y$ than smaller fish. The effect might be countered, however, as smaller fish might be able to position their mouths more finely to respire less viscous (lower $Y$ ) material between the lumps in the heterogeneous fluff. Both these effects need investigation.

As well as determining the value of $Y$, our method also determined a value for resistance $R$ through the gill system. This value, which we had anticipated to be independent of $P$, [PIM] and [POM], turned out to be negatively related to $P$, [PIM] and [POM] (Figs 5b, 6d,f). In Newtonian (i.e. non-polymeric) liquids, and at low Reynolds number $R e$, flow proceeds through a conduit from a higher to a lower reservoir, as in our system, such that the head of water, or hydrostatic pressure difference $P$ declines exponentially with time towards zero. This gives a straight-line relationship between $\log (P)$ and time $t$ (Eq. 7). In water without fluff, as shown in the typical example in Fig. 5b, we found that the slope $\log (P)$ vs. $t$ increased with increasing $t$ and decreasing $P$. This suggests that either high $R e$ values at the higher values of flow may have given extra resistance to flow as turbulent viscosity, or that high values of $P$ may have deformed the flow passages to restrict them somewhat relative to their conformation at lower pressures. Note that these hypotheses are not mutually exclusive. However, that measured resistance $R$ showed a weak but significant negative relationship with fluff concentration swings the balance of likelihood in favour of turbulent drag reduction mediated by the elastic properties of many algal exopolymers (Hoyt and Soli, 1965; Hoyt, 1970; Ramus et al., 1989; Ramus and Kenney, 1989).

Rheological properties of heterogeneous materials are scale-dependent, as shown in Fig. 2. They may be therefore strongly related to the size of the measuring system, so it is crucial to match the size and shape of the measuring system to those of the processes under investigation. In the present study this problem was overcome by using a dead fish as measuring system for rheological properties controlling processes of interest in a living fish. This technique can now be generalised, not only to other fish, but also to all other systems, whether biological, biogeochemical or industrial for example. Nevertheless, to enable better rheological characterisation and to elucidate better understanding of aggregate and molecular dynamical structure, complementary measurement of rheological properties are desirable using classical rheometrical systems, such as capillary, cone-and-plate and concentric-cylinder geometries in both continuous and oscillatory deformation (Barnes et al. 1989). Furthermore, measurements made using different tube diameters and gap sizes, will give insight into the size distribution of aggregate suspensions.

To use our results in models of the physiology and population dynamics of juvenile sole in mud flats, it will be crucial also to quantify and include behaviour. In 
particular, the interaction between raising its head, mouth and eyes, mutual perception between sole and predators such as wading birds, and the vertical distribution of rheological properties and $\mathrm{O}_{2}$ concentration in the surface few millimetres or centimetres of the fluff-sediment layer all need well co-ordinated investigation.

The present preliminary results obtained with the benthic fluff suspension as well as those found by Jenkinson and Arzul $(1998,2002)$ in rheologically thickening and ichthyotoxic phytoplankton culture, need to be cross-calibrated with classical rheological techniques. They should also be combined with studies of not only metabolite exchange at the gills and skin, but also fish behaviour and survival. To be comprehensive, such studies need to cover all stages of a fish species' life cycle, from egg and larva to adult. Several species of juvenile fish, abundant inshore off Plymouth, England were seriously impacted (Potts and Edwards, 1987) in connection with a harmful algal bloom (HAB) of Karenia mikimotoi (then known as Gyrodinium aureolum), a species now known to be both rheotoxic and cytotoxic to fish (Gentien and Arzul, 1990; Jenkinson and Arzul, 1998, 2002). The larvae of these fish, abundant before the bloom, practically disappeared. The impact of such blooms on fish yearclasses at the planktonic larval stage, although unnoticed, might be considerable, and a modified and small-scale version of our ichthyoviscometer could be used to investigate the comparative impacts of algal rheotoxicity and cytotoxicity on fish larvae.

More complete modelling of the effects of fluff and other surface sediment on the respiration of juvenile sole needs to take into account not only $\mathrm{O}_{2}$ uptake at the gills, but also secretion of waste products such as $\mathrm{CO}_{2}$ and $\mathrm{NH}_{3}$ as functions of water flow and metabolic activity. Nevertheless, the model would not be highly sensitive to these inputs because, as we have shown, cut-off in flow is rather sharp. Total cut-off occurs at values of [POM] from 4 to 7 g. $\mathrm{L}^{-1}$.

We have demonstrated the profound effect that sediment quality, and particularly the rheology of the overlying fluff, plays on sole and other juvenile fish living in this material and respiring it. Shellfish farming pressure, by increasing the production and standing stock of benthic organic fluff, may change habitat selection behaviour, and species make-up on mud-flats. Concomitantly it may both restrict the suitability of mud flats as nursery by reducing their extent and causing juveniles to use more energy thus jeopardising their survival and recruitment to stocks of commercial-size. 


\section{ACKNOWLEDGEMENTS}

We thank N. Blanc for experimental work, D. Leguay, G. Guillou, M. Bréret and Y. Descatoire for technical help, and S. Deschamps for data processing. We acknowledge financial support by the European Union, Directorate Fisheries, through contract QLRS-2002-00799, Project ETHOFISH. Fish manipulations and measurements were carried out in accordance with both French legal and ethical standards, and with Council of Europe Directive 86/609/EEC of 24 November 1986 on the approximation of laws, regulations and administrative provisions of the Member States regarding the protection of animals used for experimental and other scientific purposes, as amended by Protocol ETS No. 123 of 22 July 1998. 


\section{REFERENCES}

Alldredge AL, Granata TC, Gotschalk CC, Dickey TD (1990) The physical strength of marine snow and its implications for particle disaggregation in the ocean. Limnol Oceanogr 35: 1415-1428

Anonymous (2003) Report of the Working Group on the Assessment of the Southern Shelf Demersal Stocks. Int Couns Explor Sea CM 2003/ACFM 03

Barnes HA, Walters K (1985) The yield stress myth? Rheologica Acta 24: 323-326

Barnes HA, Hutton JF, Walters K (1989) An Introduction to Rheology. Elsevier, Amsterdam

Barillé L, Cohnie B (2000) Revival capacity of diatoms in bivalve pseudofaeces and faeces. Diatom Res 15: 11-17

Bjørnsen PK (1988) Phytoplankton exudation of organic matter. Why do healthy cells do it? Limnol Oceanogr 33: 151-154

Buscall R, Mills PDA, Goodwin JW, Lawson DW (1988) Scaling behaviour of the rheology of aggregate networks formed from colloidal particles. J Chem Soc, Faraday Trans. 1, 84: 4249-4260

Busch PL, Stumm W (1968) Chemical interactions in the aggregation of bacteria: Bioflocculation in waste treatment. Env Sci Technol 2(1): 49-53

Cheng D C-H (1986) Yield stress: A time dependent property and how to measure it. Rheologica Acta 25: 542-554

Cox RA, McCartney MH, Culkin, F (1970) Specific gravity/ salinity/ temperature relationship in natural seawater. Deep-Sea Res 17: 679-689

Culkin FC, Cox RA (1966) Sodium, potassium, magnesium, calcium and strontium in seawater. Deep-Sea Res, 13: 789-804

Dalla Valle AZ, Rivas-Diaz R, Claireaux G (2003) Opercular differential pressure as a predictor of metabolic oxygen demand in the starry flounder. J Fish Biol 63: 1578-1588

Decho AW (1990) Microbial exopolymer secretions in ocean environments: their role(s) in food webs and marine processes. Oceanogr mar Biol ann Rev 28: 73153

Ferry-Graham LA (1999) Mechanics of ventilation in swellsharks, Cephaloscyllum ventriosum (Scyliorhinidae). J exp Biol 202: 1501-1510

Galois R, Blanchard G, Seguignes M, Huet V, Joassard L (2000) Spatial distribution of sediment particulate organic matter on two estuarine intertidal mudflats: a comparison between Marennes-Oleron Bay (France) and the Humber Estuary (UK). Cont Shelf Res 20: 1199-1217

Gentien P, Arzul G (1990) Exotoxin production by Gyrodinium cf. aureolum (Dinophyceae). J mar biol Ass UK 70: 571-581

Holeton GF, Jones DR (1975) Water flow dynamics in the respiratory tract of the carp (Cyprinus carpio L.). J Exp Biol 63: 537-549

Hoyt JW (1970) High molecular weight algal substances in the sea. Mar Biol 7:93-99

Hoyt JW, Soli G (1965) Algal cultures: Ability to reduce turbulent friction in flow. Science 149: 1509-1511

Hughes GM (1960) A comparative study of gill ventilation in marine teleosts. J Exp Biol 37: 28-45

Hughes GM (1965) Comparative Physiology of Vertebrate Respiration, Vol. 2. Harvard Univ Press Cambridge MA.

Hughes GM (1984) General anatomy of the gills. In: Hoar WS, Randall DJ (eds) Fish Physiology, Vol. 10A. Academic Press Inc Orlando pp 1-72

Hughes GM, Morgan M (1973) The structure of fish gills in relation to their function. Biol Rev 48: 419-475 
Hughes GM, Shelton, G (1958) The mechanism of gill ventilation in three freshwater teleostean fishes. J exp Biol 35: 807-823

Jenkinson IR (1986) Oceanographic implications of non-newtonian properties found in phytoplankton cultures. Nature 323: 435-437

Jenkinson IR (1993a) Viscosity and elasticity of Gyrodinium cf. aureolum and Noctiluca scintillans exudates in relation to mortality of fish and damping of turbulence. In: Smayda TJ, Shimizu Y (eds) Toxic Phytoplankton Blooms in the Sea. Elsevier Amsterdam, pp 757-762

Jenkinson IR (1993b) Bulk-phase viscoelastic properties of seawater. Oceanologica Acta 16: 317-334

Jenkinson IR, Arzul G (1998) Effect of the flagellates, Gymnodinium mikimotoi, Heterosigma akashiwo and Pavlova lutheri, on flow through fish gills. In: Reguero B, Blanco J, Fernández ML, Wyatt T. (eds) Harmful Algae. Xunta de Galicia Pontevedro and Intergovernmental Oceanographic Commission of Unesco Paris pp 425-428

Jenkinson IR, Arzul G (2002) Mitigation by cysteine compounds of rheotoxicity, cytotoxicity and fish mortality caused by the dinoflagellates, Gymnodinium mikimotoi and G. cf. maguelonnense. In: Hallegraeff GM, Blackburn SI, Bolch CJ, Lewis RJ (eds) Harmful Algal Blooms 2000. Intergovernmental Oceanographic Commission of Unesco Paris pp 461-464

Jenkinson IR Biddanda BA (1996) Bulk-phase viscoelastic properties of seawater: relationship with plankton components. J Plankton Res 17: 2251-2274

Koutsikopoulos C, Désaunay Y, Dorel D, Marchand J (1989) The role of coastal areas in the life history of sole (Solea solea (L.)) in the Bay of Biscay. Scient mar 53: 567-575

Langille BL, Stevens ED, Antanaraman A (1983) Cardiovascular and respiratory flow dynamics. In: Webb PW, Weihs D (eds) Fish Biodynamics. Praeger Publishers New York pp 92-139

Lauder GV (1984) Pressure and water flow patterns in the respiratory tract of the bass (Micropterus salmoides). J exp Biol 113: 151-164

Léauté, J-P, Caill-Milly N (2003) Les petites pêches côtières et estuariennes françaises de sud du Golfe de Gascogne. Rapport final du contrat PECOSUD EC/DG Fish (DG XIV) No. 99/024, Ifremer, DRV/RH/DT/03-01

Li D-H, Ganczarczyk JJ (1986) Physical characteristics of activated sludge flocs. Critical Reviews in Environmental Control 17(1): 53-87

Malte H (1989) Pressure/flow relations in the interlamellar space of fish gills: Theory and application in the rainbow trout. Respir Physiol 78: 229-241

Mari X, Kiørboe T (1996) Abundance, size distribution and bacterial colonization of transparent exopolymeric particles (TEP) during spring in the Kattegat. J Plankton Res 18: 969-986

Massel SR (1999) Fluid Mechanics for Marine Ecologists. Springer-Verlag, Berlin

Miyake Y, Koizumi M (1948) The measurement of the viscosity coefficient of sea water. J mar Res 7: 63-66

Olianas A, Fadda MB, Boffi A, Murenu M, Deiana AM, Sarti P (1995) Benthic mucilaginous aggregates: Biochemical characterization and ligand binding properties. Mar environm Res 41: 1-14

Passow U (2002) Transparent exopolymer particles (TEP) in aquatic environments. Prog Oceanogr 55: 287-333

Piiper J, Scheid P (1984) Model analysis of gas transfer in fish gills. In: Hoar WS, Randall DJ (eds) Fish Physiology, Vol 10A. Academic Press Inc Orlando pp 229-261. 
Potts GW, Edwards JM (1987) The impact of a Gyrodinium aureolum bloom on inshore young fish populations. J mar Biol Ass UK 67: 293-297

Pouvreau S, Jonquières G, Buestal D (1999) Filtration by the pearl oyster, Pinctada margaritifera, under conditions of low seston load and small particle size in a tropical lagoon habitat. Aquaculture 176: 295-314

Ramus J, Kenney BE (1989) Shear degradation as a probe of microalgal exopolymer structure and rheological properties. Biotechnol Bioeng 34: 1203-1208

Ramus J, Kenney BE, Shaughnessey EJ (1989) Drag reducing properties of microalgal exopolymers. Biotechnol Bioeng 33: 550-557

Randall D, Daxboeck C (1984) Oxygen and carbon dioxide transfer across fish gills. In: Hoar WS, Randall DJ (eds) Fish Physiology Vol 10A. Academic Press Inc Orlando pp 263-314

Ransom B, Bennett RH, Baerwald R, Hulbert MH, Burkett P-J (1999) In situ conditions and interactions between microbes and minerals in fine-grained marine sediments: A TEM microfabric perspective. Am Mineralogist 84: 183192

Schulze, von B, Brauns J, Schwalm I (1991) Neuartiges baustellen-meßgerät zur bestimmung der fließgrenze von suspensionen. Geotechnik 14: 125-131

Shelton G (1970) The regulation of breathing. In: Hoar WS, Randall DJ (eds) Fish Physiology, Vol. 4, Academic Press New York pp 293-359.

Sornin J-M, Feuillet M, Héral M, Fardeau J-C (1986) Influence of oyster farming Crassostrea gigas on the phosphate cycle in an intertidal zone: The role of biodeposition. Oceanologica Acta 9: 313-322

Spinosa L, Lotito V (2003) A simple method for evaluating sludge yield stress. Adv environm Res 7: 655-659

Stevens ED (1972) Some aspects of gas exchange in tuna. J exp Biol 56:809-823

Summers AP, Ferry-Graham LA (2001) Ventilatory modes and mechanics of the hedgehog skate (Leucoraja erinacea): Testing the continuous flow model. J exp Biol 204: 1577-1587

Sutherland TF, Grant J, Amos CL (1998) The effect of carbohydrate production by the diatom Nitzschia curvilineata on the erodibility of sediment. Limnol Oceanogr 43: 65-72

Underwood GJC, Boulcott M, Raines CA Waldron K (2004) Environmental effects on exopolymer production by marine benthic diatoms: dynamics, changes in composition, and pathways of production. J Phycol 40: 293-304

Verdugo P, Alldredge AL, Azam F, Kirchman DL, Passow U., Santschi PH (2004) The oceanic gel phase: a bridge in the DOM-POM continuum. Mar Chem 92: 67-85

Wells ML, Goldberg, ED (1993) Colloid aggregation in seawater. Mar Chem, 41: 353-358 


\section{APPENDIX - DETERMINATION OF CONFIDENCE LIMITS FOR FLOW}

This appendix shows how the data presented, especially Fig 6e,f, have been used to derive 95\% confidence limits for flow through the gills of a 26-g sole, one that produces in vivo a maximum hydrostatic pressure difference $P$ across its gills of 4.8 $\mathrm{Pa}$ (Eq. 11). We use the same dimensional units for each variable as those in the body of the paper.

These confidence limits take into account variability due only to scatter in the experimental data, that is two deformational properties of the fluff, $Y$ and $R$, in relation to its particulate organic matter concentration [POM]. Any possible systematic departure between the model we propose and $F$ in vivo has not been taken into account, and this requires future investigation in live fish.

Fig. 7 shows the best fit for cross-gill flow rate $F$ vs. [POM] for fishes of different masses $M$ as a function of $P$. Equation 14 shows how $F(\mathrm{POM})$ is related to $P, R(\mathrm{POM})$ and $Y(\mathrm{POM})$ and thence to [POM].

Fig. 6e shows the best fit for $Y$ and Appendix Fig. 1a (thick, ascending lines) repeats this best fit as $Y(\mathrm{POM})$ along with the upper and lower $95 \%$ confidence limits of $Y(\mathrm{POM})$, respectively $Y h i(\mathrm{POM})$ and $Y l o(\mathrm{POM})$.

As physically $Y$ cannot be negative,

$$
\begin{array}{ll}
Y(\mathrm{POM})=-27+9.7 .[\mathrm{POM}] \text { if }>0 \text {, else } 0 & \text { Equation A.1a } \\
Y h i(\mathrm{POM})=-14+12 .[\mathrm{POM}] \text { if }>0 \text {, else } 0 & \text { Equation A.1b } \\
Y l o(\mathrm{POM})=-40+8.0 .[\mathrm{POM}] \text { if }>0 \text {, else } 0 & \text { Equation A.1c }
\end{array}
$$

Similarly, Fig. $6 f$ shows the best fit for $R$ along with the upper and lower $95 \%$ confidence limits of $R(\mathrm{POM})$, respectively $R h i(\mathrm{POM})$ and $R l o(\mathrm{POM})$.

$$
\begin{array}{ll}
R(\mathrm{POM})=4.4 \times 10^{6}-0.26 \times 10^{6} . \mathrm{POM} & \text { Equation A.2a } \\
R h i(\mathrm{POM})=5.2 \times 10^{6}-0.16 \times 10^{6} . \mathrm{POM} & \text { Equation A.2b } \\
R l o(\mathrm{POM})=3.6 \times 10^{6}-0.36 \times 10^{6} . \mathrm{POM} & \text { Equation A.2c }
\end{array}
$$

Given Equation 14, in a hypothetical case where $R$ were perfectly known and there were no variation in $R$, the upper and lower $95 \%$ confidence limits for $F(\mathrm{POM})$ could be expressed by combining Equation 14 with Equations A.1b and A.1c respectively thus.

$$
\begin{array}{ll}
\text { FhiY }(P O M)=\frac{P-Y l o(P O M)}{R(P O M)} \text { if }>0, \text { else } 0 & \text { Equation A.3b } \\
\text { FloY }(P O M)=\frac{P-Y h i(P O M)}{R(P O M)} \text { if }>0, \text { else } 0 & \text { Equation A.3c }
\end{array}
$$


Similarly, in a hypothetical case where $Y$ were perfectly known and there were no variation in $Y$, the upper and lower 95\% confidence for $F(\mathrm{POM})$ could be expressed by combining Equation 14 with Equations A.2b and A.2c respectively thus:

$$
\begin{array}{ll}
\text { FhiR }(P O M)=\frac{P-Y(P O M)}{R l o(P O M)} \text { if }>0, \text { else } 0 & \text { Equation A.4b } \\
\text { FloR }(P O M)=\frac{P-Y(P O M)}{R h i(P O M)} \text { if }>0, \text { else } & \text { Equation A.4c }
\end{array}
$$

The combined residual of the 95\% confidence limit relative to the best fit is the root sum of squares of the residuals of each confidence limit. The upper and lower 95\% confidence limits for flow are thus:

$$
\begin{aligned}
& F h i(P O M)=F(P O M)+\left\{\left[(F h i Y(P O M)-F(P O M)]^{2}+[F h i R(P O M)-\right.\right. \\
& \left.F(P O M)]^{2}\right\}^{0.5} \quad \text { if }>0 \text {, else } 0 \quad \text { Equation A.5b } \\
& \text { Flo }(P O M)=F(P O M)-\left\{\left[(F l o Y(P O M)-F(P O M)]^{2}+[\text { FloR }(P O M)-\right.\right. \\
& \left.F(P O M)]^{2}\right\}^{0.5} \quad \text { if }>0 \text {, else } 0 \quad \text { Equation A.5c }
\end{aligned}
$$

Fig. A.1b shows $F(P O M)$ plotted against [POM] for a hydrostatic pressure difference $P$ of $4.8 \mathrm{~Pa}$. The uncertainty in the value of [POM] at which flow stops (i.e. $F(P O M)$ intersects 0$)$ is mainly due to uncertainty in $Y$, while the uncertainty in the value of $F(0)$ is entirely due to uncertainty in $R(0)$. The asymmetry in the vertical distance of $F h i(P O M)$ and Flo(POM) from $F(P O M)$ is due to the non-linearity inherent in Equation 14.

Fig. A.1b shows a sharp inflexion in both $F$ and Fhi where [POM] equals 2.8, corresponding to the value of $[\mathrm{POM}]$ at which $Y$ intersects zero and inflects (Fig A.1a). The curve of Flo inflects where [POM] equals 1.2, corresponding to the value of [POM] at which Ylo intersects zero and inflects, while the curve of Fhi inflects a second time at $[\mathrm{POM}]$ equal to 3.3 , corresponding to the value of [POM] at which $F$ falls to zero, and at which $P=Y$.. The curves show that the relationship between flow rate $F$ and fluff organic matter concentration ([POM]) are highly non-linear. 


\section{FIGURE LEGENDS}

Fig. 1

The study area.

Fig. 2

Effect of tube diameter and sludge suspension concentration on yield stress of sewage sludge, measured using a Kasumeter.

Drawn (with permission) from data published by Spinosa and Lotito (2003) (their Table 2).

Fig. 3

The Kasumeter.

Redrawn from Schulze et al. (1991). Not to scale.

Fig. 4.

Diagram of the ichthyoviscometer, showing the position of the dead sole in the large reservoir (right). Water flows from the small reservoir (left) through a short pipe, the tap (V), and the flexible conical tube, into the mouth of the sole, through its gills, the branchial chambers, and out through the opercula (arrows) into the large reservoir. "h" indicates the height between water levels in the small and large reservoirs. This is proportional to the hydrostatic pressure difference $P$ across the gills of the fish, and was measured using the pair of hydrostatic pressure probes, one in each reservoir, connected to a differential pressure sensor, and recorded using a personal computer. See text for the dimensions.

Fig. 5

Examples of plots of hydrostatic pressure difference $P$ vs. time $t$, obtained with the ichthyoviscometer. Panels a and b: experimental fluid was pure seawater; Panels c and $\mathrm{d}$ : experimental fluid was $50 \%$ suspension of fluff $\left([\mathrm{POM}]=8.4 \mathrm{~g} . \mathrm{L}^{-1}\right)$. Panels a and c: linear plots; Panels b and d: log-linear plots of the same data. In Panel b, the values of $P$ have been increased by $10 \mathrm{~Pa}$ to avoid log-transformations of zero or negative values. The greater noise evident in Panels $c$ and $d$ relative to that in $a$ and $b$ is due to the action of the magnetic follower, which was not activated for the trial involving pure seawater.

Fig. 6

Relationships of $R$ and $Y$, biorheological parameters of flow through the sole gills vs. components of the sediment, concentrations of particulate inorganic matter [PIM] and particulate organic matter [POM]. a) [POM] vs. [PIM]; b) $R$ vs. $Y$; c) $Y$ vs. [PIM]; d) $R$ vs. [PIM]; e) $Y$ vs. [POM]; f) $R$ vs. [POM]. Shown as insets are the best-fit regressions with 95\% confidence limits for the intercepts and slopes, and correlation coefficients $\left(\mathrm{r}^{2}\right)$. Note that, to avoid clutter in $\mathrm{b}$, $\mathrm{d}$ and $\mathrm{f}$, the units of $R$ are shown as $\mathrm{mm}^{-2} \cdot \mathrm{s}^{-1}$ on the $\mathrm{y}$-axes but as $\mathrm{m}^{-2} \cdot \mathrm{s}^{-1}$ in the regression equations. Note also that $\mathrm{R}=$ K. $\eta_{W}$, where $\eta_{W}$ is the viscosity of the seawater phase of the fluff, $1.224 \times 10^{-3} \mathrm{~kg} . \mathrm{m}^{-}$ ${ }^{1} \cdot \mathrm{s}^{-1}$.

Fig. 7

Flow rate $F$ vs. [POM] in respired fluff, modelled as a function of hydrostatic pressure difference $P[\mathrm{~Pa}]$ in vivo, and corresponding fish mass $[\mathrm{g}]$ and maximum developed $P$ (Eq. 11). Note that for all the curves, we show in the Appendix that the slight positive 
slope in the left part of the graph of $F$ vs. [POM] is not significantly different from zero.

Appendix Figure 1.

Ventilatory flow parameters (most likely value with upper and lower 95\% confidence limits) for a 26-g sole as a function of fluff particulate organic matter concentration [POM]. Panel a shows $Y$ (thick ascending lines) and $R$ (fine descending ones). Panel b shows expected flow $F$ (most likely value with upper and lower 95\% confidence limits). 

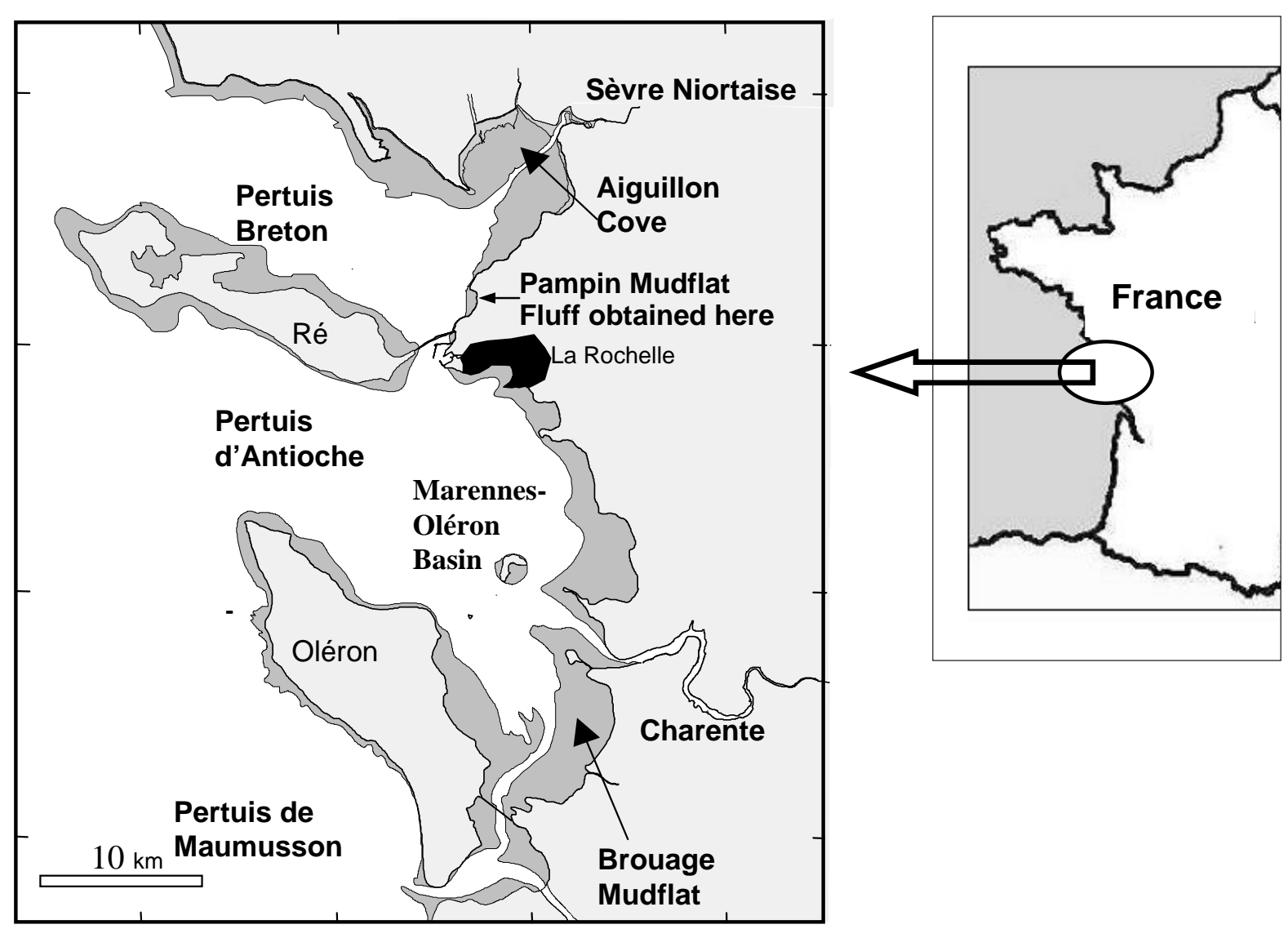

Jenkinson et al. 


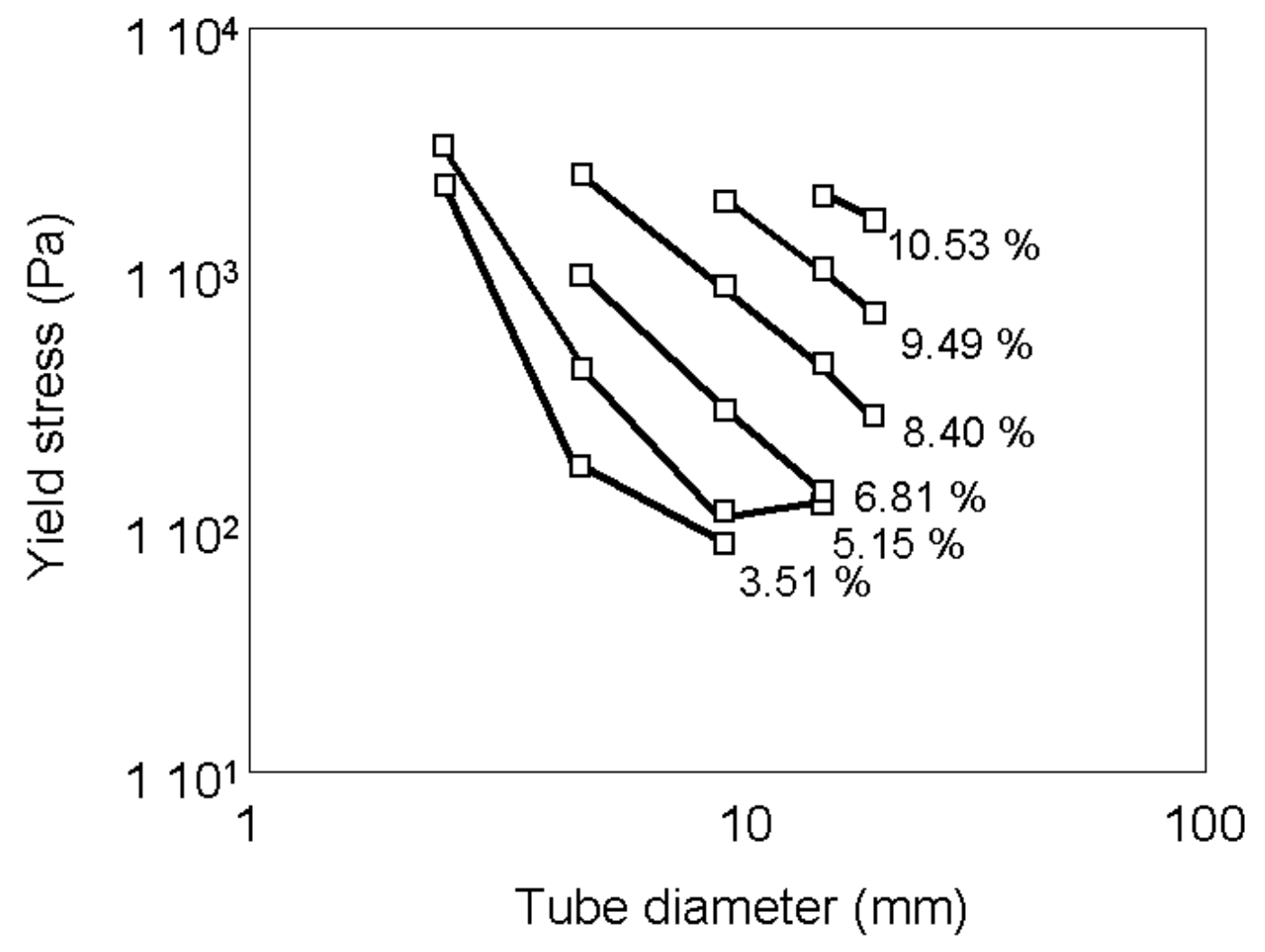

Fig. 2 


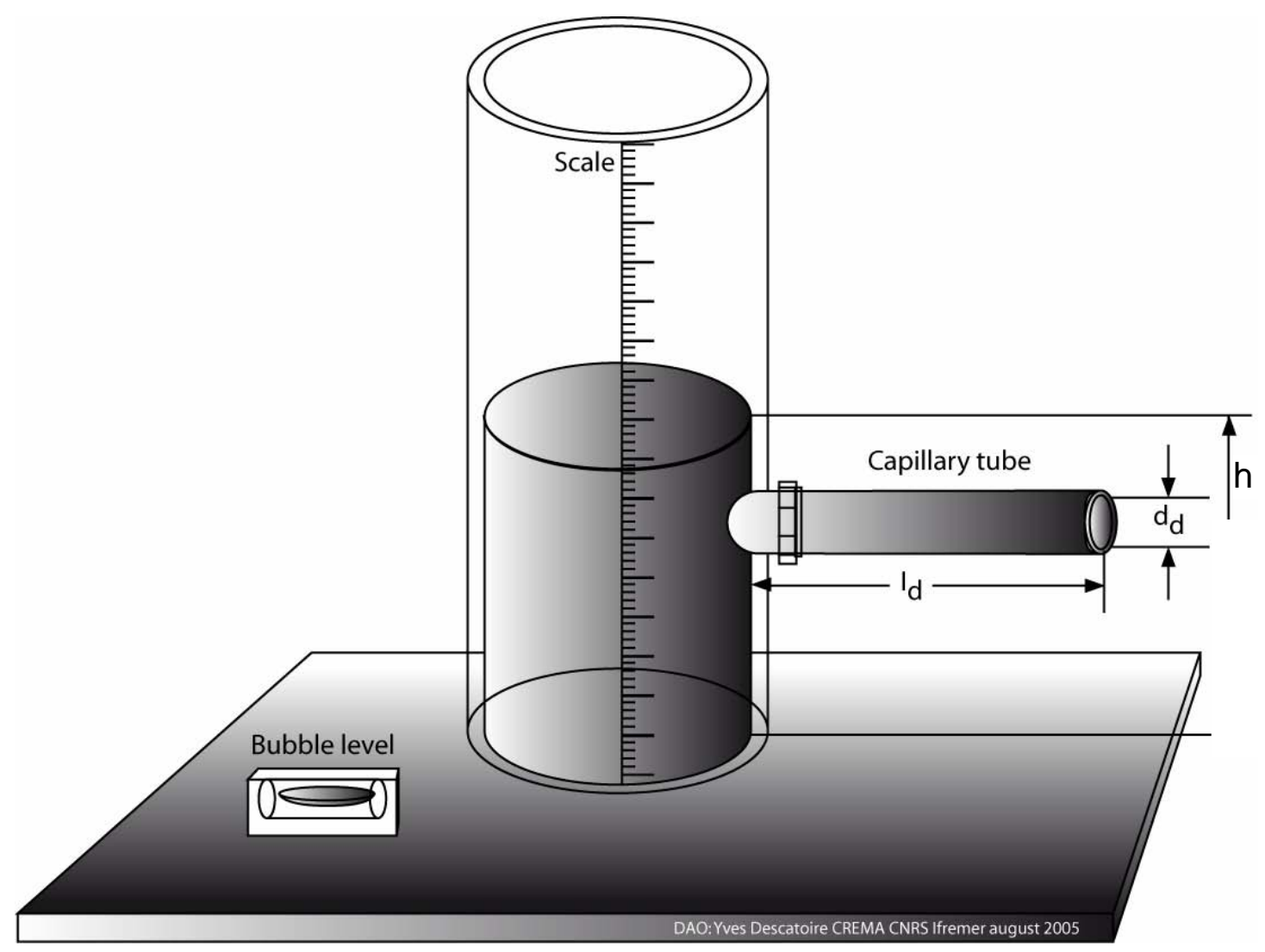

Fig. 3

Jenkinson et al. 


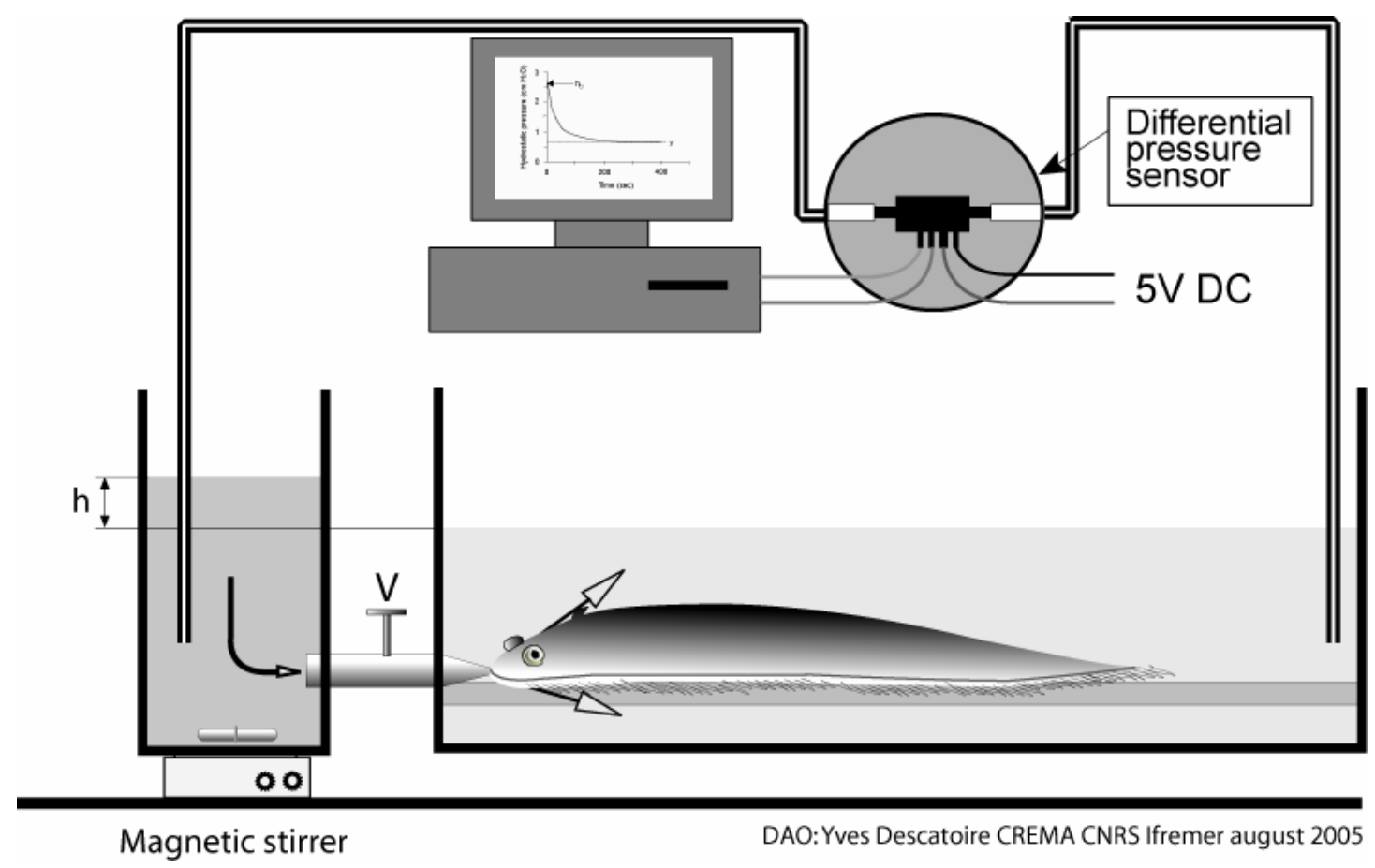

Fig. 4

Jenkinson et al. 

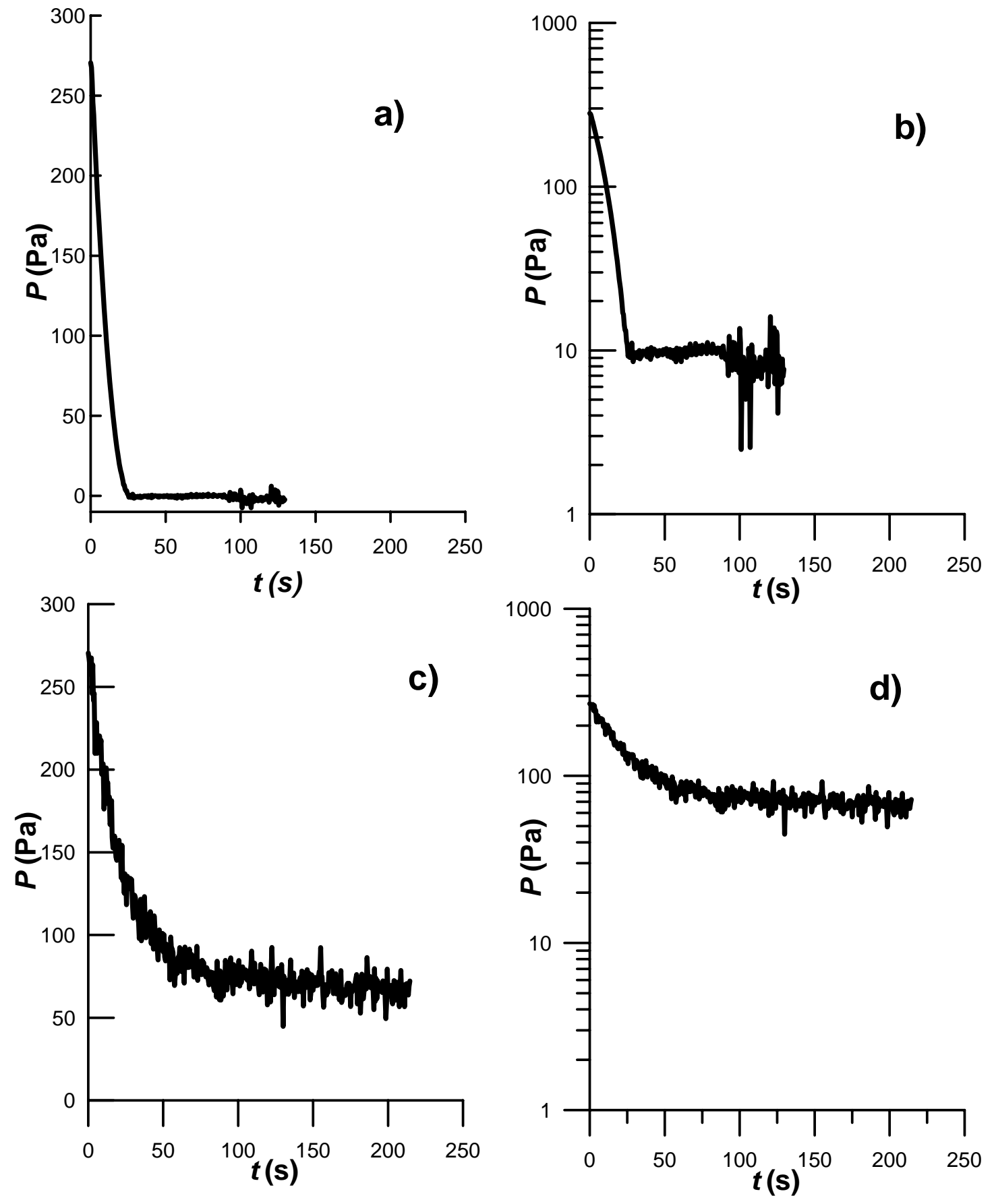

Fig. 5

Jenkinson et al. 

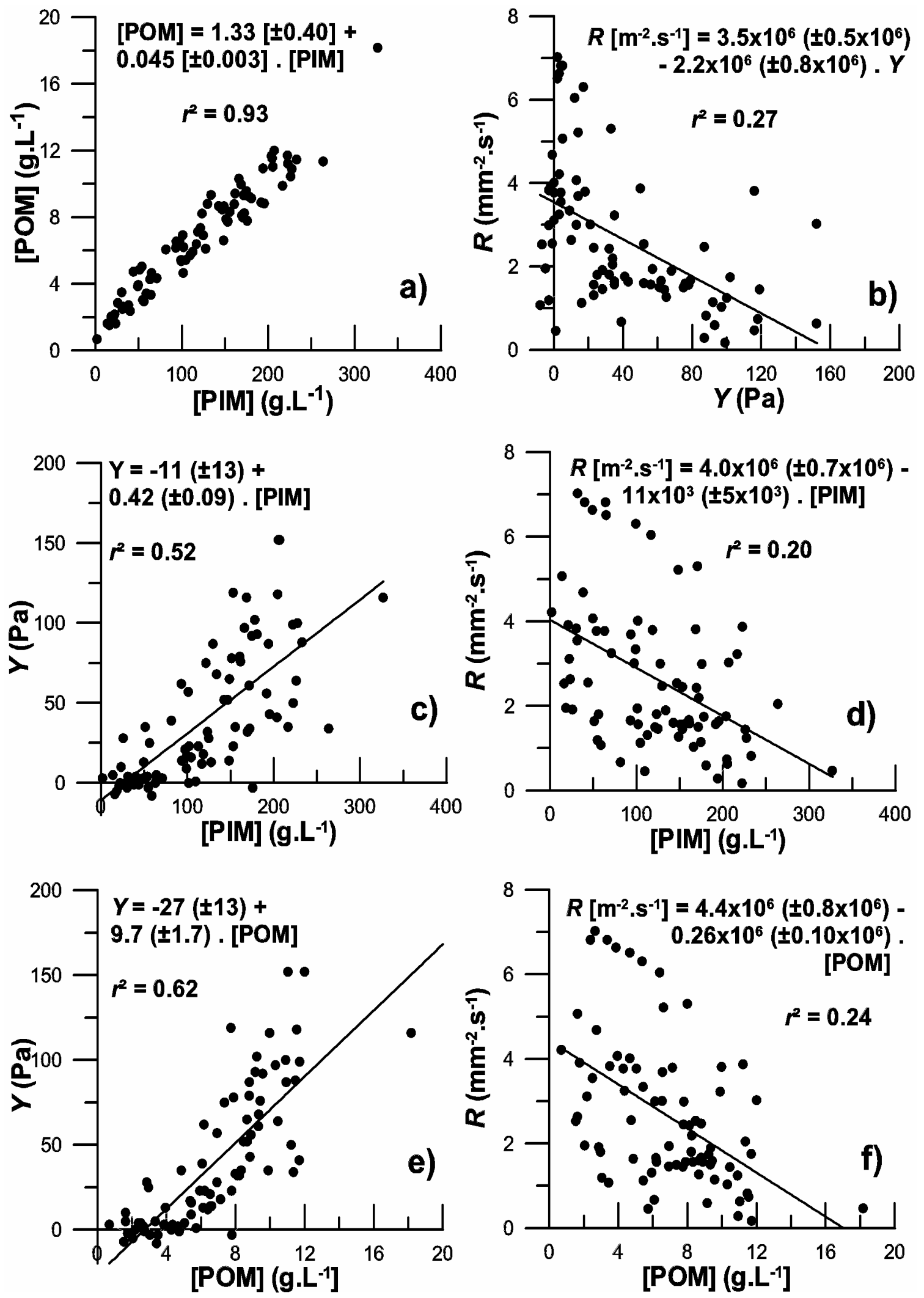

Fig. 6

Jenkinson et al. 


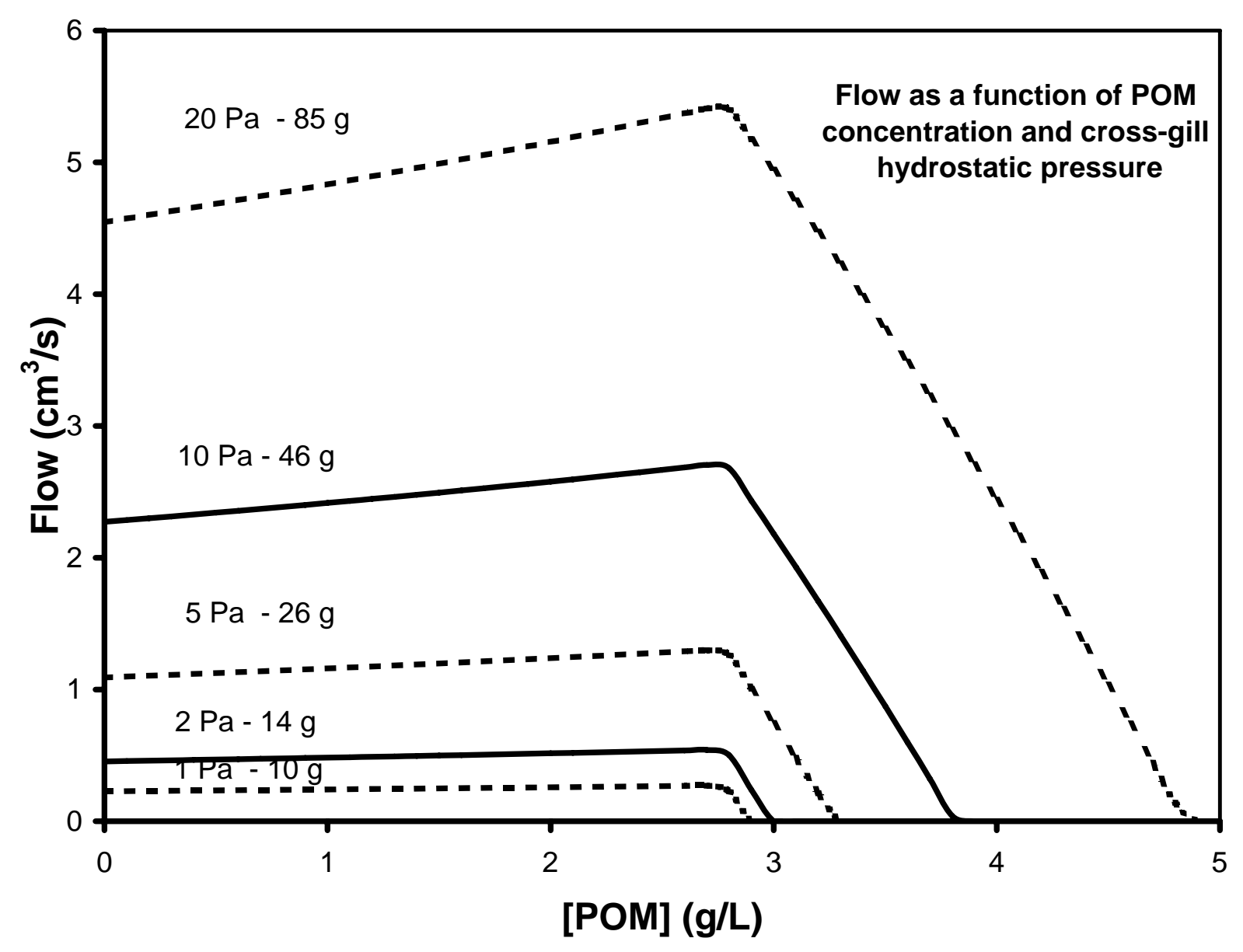

Fig. 7

Jenkinson et al. 

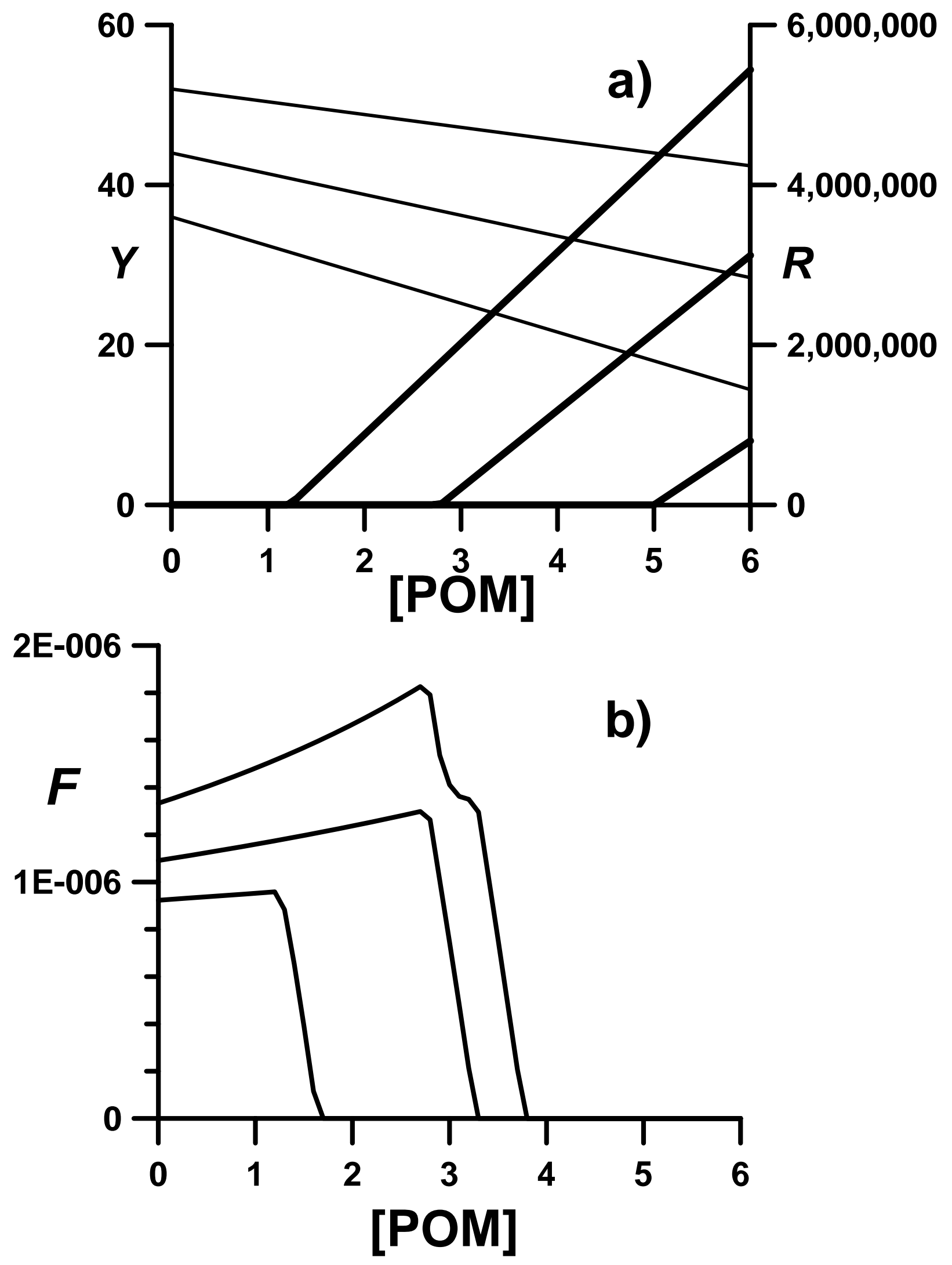

Fig. A1 